\title{
Addressing a Judge in National Varieties of English
}

\author{
Vladimir Ozyumenko \\ RUDN University \\ Moscow, Russia
}

\begin{abstract}
Despite the fact that legal discourse is intended to be clear, precise and unambiguous, in legal terminology there are obvious signs of cultural variability that can be observed not only in different languages, but also in varieties of the same language. Ignorance of cultural differences in legal terminology and legal discourse can lead to serious complications in an intercultural context. This study is limited to terms of reference and forms of address to judges of different levels in the British, Irish, American, Canadian, Australian and New Zealand varieties of English in a courtroom setting. The goal of the study is to analyze the terms of references and forms of address to judges in these varieties of English, identify their similarities and culture specific features and try to find the reasons for the differences. The data were obtained from various sources: dictionaries, legal documents, newspapers, as well as some secondary sources (Brown \& Rice 2007, Hickey 2008, McPeake 2010) and Internet resources. They were analysed drawing on studies of pluricentric languages (Clyne 1992, Kloss 1967, Leitner 1992, Muhr \& Marley 2015), World Englishes Paradigm (Bolton 2006, 2017; Crystal 2003, Domashnev 2000, Kachru 1985, 1986, 1988, 2008; Low \& Pakir 2017, Proshina 2012, 2017, 2019); implementing comparative, semantic, pragmatic, discursive and cultural analysis. To explain some of the results, the legal and political systems of the countries that speak the national varieties of English were analysed. Preliminary results of the study revealed both similarities and differences in the terms of reference and forms of address to judges of various ranks, caused by a nexus of historical, political and social reasons that require further study. Among these, one can note the degree of openness of society to the democratization of its legal system, the country's desire to either follow the traditions established in British judicial discourse, or to demonstrate their uniqueness and independence from the former colonial power. Despite its limited nature, the study provides some new data showing that the lexical and discursive variability observed in the legal sphere contributes to the formation of varieties of pluricentric languages. The results can contribute to the study of pluricentric languages, find application in lexicographic practice, as well as in the teaching of legal English to law students.
\end{abstract}

Keywords: court discourse, judge, terms of reference, forms of address, varieties of English

For citation:

Ozyumenko, Vladimir. 2020. Addressing a judge in national varieties of English. Russian Journal of Linguistics 24 (1). 137-157. DOI: 10.22363/2687-0088-2020-24-1-137-157. 
Научная статья

\title{
Формы обращения к судье в национальных вариантах английского языка
}

\author{
В.И. Озюменко \\ Российский университет дружбы народов \\ Москва, Россия
}

\begin{abstract}
Аннотация
Несмотря на то что юридический дискурс призван быть ясным, точным и недвусмысленным, в юридической терминологии имеются явные признаки культурной вариативности, которые можно наблюдать не только в разных языках, но и в вариантах одного и того же языка. Незнание культурных различий в юридической терминологии и юридическом дискурсе может привести к серьезным осложнениям в межкультурном контексте. Данное исследование ограничено терминами, обозначающими судей разного уровня и формами обращений к ним в британском, ирландском, американском, канадском, австралийском и новозеландском вариантах английского языка в ситуации судебного заседания. Цель исследования - проанализировать термины референций и формы обращений к судьям в данных вариантах английского языка, выявить их сходства и культурно-специфичные особенности и попытаться найти причины существующих различий. Материал был собран из различных источников: словарей, юридических документов, газет, а также некоторых вторичных источников - учебников, книг по этикету (Brown \& Rice 2007, Hickey 2008, McPeake 2010), в том числе и интернет-ресурсов. Данные были проанализированы с опорой на исследования плюрицентричных языков (Clyne 1992, Kloss 1967, Leitner 1992, Muhr \& Marley 2015), контактной вариантологии английского языка (Bolton 2006, 2017; Crystal 2003, Kachru 1985, 1986, 1988, 2008; Low \& Pakir 2017, Proshina 2019, Домашнев 2000, Прошина 2012, 2017 и др.) с применением сравнительного, семантического, прагматического, дискурсивного и культурологического анализа. Для объяснения некоторых результатов были проанализированы правовые и политические системы стран, говорящих на основных вариантах английского языка. Предварительные результаты исследования выявили как сходства, так и различия, которые наблюдаются в наименованиях судей различного ранга и в формах обращения к ним, обусловленные комплексом исторических, политических и социальных причин, которые требуют специального дальнейшего изучения. Среди них можно отметить степень открытости общества к демократизации его правовой системы, стремление страны либо следовать традициям, установленным в британском судебном дискурсе, либо демонстрировать свою уникальность и независимость от бывшей метрополии. Несмотря на ограниченный характер, исследование дает новые данные, иллюстрирующие, что лексическая и дискурсивная вариативность, наблюдаемая в юридической сфере, способствует формированию вариантов плюрицентричных языков и может рассматриваться как формирующий их компонент. Результаты могут способствовать изучению плюрицентричных языков, найти применение в лексикографической практике, а также в преподавании юридического английского.
\end{abstract}

Ключевые слова: судебный дискурс, судья, термины референции, формы обращения, варианты английского языка

\section{Для цитирования:}

Озюменко В.И. Формы обращения к судье в национальных вариантах английского языка // Russian Journal of Linguistics. 2020. T. 24. No 1. C. 137-157. DOI: 10.22363/26870088-2020-24-1-137-157. 


\section{Введение}

Формы обращения наглядно демонстрируют то, как социальные отношения и культурные ценности отражаются в социальных категориях, в лексической системе языка и дискурсивных практиках. Кроме того, они являются маркером происходящих в обществе социальных процессов, отражающихся как в самих терминах, так и их функционировании.

Как показали многочисленные исследования, в каждой культуре есть своя система форм обращений и правил их использования, которые отражают социокультурные особенности того или иного лингвокультурного сообщества (Afful 2006; Aliakbari, Arman 2008; Chesnokova 1996; Clyne 2009; Clyne et al. 2009; Khalil et al. 2018; Larina \& Khalil 2018; Rhee 2019, Wierzbicka 2013, Которова 2018 и др.). Исследования форм обращений в различных вариантах одного и того же языка дают особенно интересные результаты, свидетельствующие о влиянии социокультурных факторов на набор форм обращений и их функционирование, что было показано в ряде работ (Hughson 2009; Larina \& Suryanarayan 2013, Wong 2006, Ларина, Сурьянараян, Юрьева 2019 и др.).

Выбор правильной формы обращения является важным условием успешной и эффективной коммуникации в любой ситуации общения и в любом типе дискурса. Для нашего исследования был выбран судебный дискурс. Несмотря на то что юридический дискурс в целом призван быть ясным, точным и недвусмысленным, в юридической терминологии имеются явные признаки культурной вариативности, которые можно наблюдать не только в разных языках, но и в вариантах одного и того же языка (см. например, Озюменко, Чилингарян 2015, Озюменко 2016, Chilingaryan et al. 2016a, 2016b и др.). Незнание культурных различий в юридической терминологии и юридическом дискурсе может привести к сложностям в контексте межкультурного общения.

Судебный дискурс характеризуется высоким уровнем формальности, что в значительной степени проявляется и в формах обращения. Использование неправильной формы обращения воспринимается как знак неуважения к судье. Инструкции по соблюдению судебного этикета предупреждают, что игнорирование правил этикета может негативным образом повлиять на исход дела (McPeake 2010) или привести к санкциям, начиная от строгого предупреждения до отмены слушания ${ }^{1}$.

Однако следовать правилам этикета не так легко. Как показывают наблюдения, наименования судей в различных культурах и юрисдикциях отличаются разнообразием. Кроме того, то, как обратиться к судье, зависит и от суда, в котором проходит слушание. Чем сложнее судебная система, тем сложнее и формы обращения, что наглядно видно на примере английских судов. Иллюстрацией может послужить история молодого английского адвоката, в которой он размышляет над проблемой обращения к судье и приводит целый список

${ }^{1}$ https://www.wikihow.com/Address-a-Female -Attorney 
возможных обращений, выбор которых в значительной степени предопределяется иерархией как судов, так и судей:

В Англии и Уэльсе при обращении к судье легко ошибиться. К судьям местных судов и непрофессиональным мировым судьям принято обращаться Sir или Madam. К судьям уголовного суда - Your Honour (Ваша честь), а если они заседают в Центральном уголовном суде Лондона (the Old Bailey) или являются почетными судьями (рекордерами), то к ним следует обращаться My Lord или My Lady. Только не перепутайте с обычными рекордерами, к которым следует обращаться Your Honour. А если судья уголовного суда заседает в Апелляционном Суде, то в тот день к нему следует обращаться My Lord. Традиционное обращение к судьям апелляционного суда - My Lord или My Lady. К судьям Bepховного Суда также принято обращаться Мy Lord или My Lady, но только потому, что все они (за исключением одного) имеют титулы лорда или леди. Не могу себе представить, как мы будем обращаться к ним, когда назначат еще несколько судей, не имеющих титула пэра ${ }^{2}$ (Перевод наш. - B.O.)

Он заканчивает свой рассказ коммуникативной неудачей, связанной с неверным выбором формулы обращения к судье, которая показывает, к каким последствиям может привести подобная ошибка:

Однажды после слушания дела об убийстве в Центральном уголовном суде Лондона (где принято обращение My Lord) я участвовал в заседании магистратского суда в Хайбери и по привычке обратился к мировому судье My Lord. Ему это понравилось, и он вынес очень мягкий приговор. Но все присутствующие, очевидно, подумали, что я придурок (Там же).

В данной статье мы рассматриваем не только вариативность наименований судей и форм обращений к ним в британском английском, но и в других вариантах английского языка, что в еще большей степени усложняет задачу правильного выбора формы обращения.

\section{1. Вариативность английского языка}

Английский язык, как известно, является плюрицентричным ${ }^{3}$ и существует во множестве вариантов, в каждом из которых отражена культура и менталитет его носителей. Теория вариантов английского языка, или в английской терминологии World Englishes Paradigm, в первую очередь связана с именем Б. Качру и его моделью трех концентрических кругов (Kachru 1985, 1988). Согласно этой теории все варианты английского языка образуют три круга: внутренний (Inner Circle), внешний (Outer circle) и расширяющийся (Expanding

\footnotetext{
${ }^{2}$ The Circuit Brief http://thecircuitbrief.blogspot.com/2011/02/addressing-judge-in-court.html

${ }^{3}$ Используется также термин полицентричный (policentric) (Scherrer, Samardžić, Glaser 2019).
} 
Circle). Во внутренний круг входят страны, где английский язык исторически является официальным языком страны и родным для его носителей. Во внешний - страны, относящиеся к бывшим колониям, где английский язык имеет статус второго официального языка, наряду с родными языками (Индия, Пакистан, ЮАР, Нигерия и др.). Расширяющийся круг включает все остальные страны, где признается значимость английского языка и он используется в качестве языка-посредника для межкультурного общения (Китай, Япония, Греция, Польша, Россия и др.).

Теория трех кругов Б. Качру позволила разделить варианты английского языка на три основных типа: национальные, региональные и локальные (Прошина 2017: 40). Национальный вариант, в отличие от национально гомогенного языка, свойствен и многоэтническому сообществу, в котором он выполняет роль кодифицированного, нормированного языка этнического большинства, выполняет официальную, регуляторную и другие функции и имеет высокий социальный престиж (Прошина 2017: 41).

Имея несколько центров, английский язык по праву считается плюрицентричным. Он соответствует всем основным критериям плюрицентричности, среди которых ученые (Clyne 1992: 1, Muhr 2012: 30) выделяют следующие:

1) язык встречается как минимум в двух странах, которые функционируют как «взаимодействующие центры» (Clyne 1992: 1);

2) должен иметь достаточно лингвистических (и/или прагматических) характеристик, которые отличают его от других и тем самым могут служить средством выражения идентичности и социальной уникальности;

3) язык должен иметь официальный статус государственного языка как минимум в двух странах (например, немецкий язык в Австрии и Германии); или, по крайней мере, регионального языка (например, немецкий язык в Италии или каталанский во Франции);

4) языковое сообщество должно признавать статус своего языка как плюрицентрической разновидности и рассматривать его как часть своей социальной / национальной идентичности.

Кроме того, язык должен быть кодифицированным, обладать стандартом, преподаваться в школах, продвигаться и распространяться (Clyne 1992: 1, Muhr 2012: 30).

Плюрицентричные языки, по справедливому замечанию М. Клайна, как объединяют, так и разъединяют людей (Clyne 1992: 1). Объединяют через использование языка, а разъединяют через развитие национальных норм и языковых особенностей, с которыми идентифицируют себя носители того или иного варианта (Там же).

В данном исследовании мы ограничились вариантами английского языка внутреннего круга (Inner Circle), куда исследователи включают 6 вариантов американский, британский, ирландский, канадский, австралийский и новозеландский (Crystal 2003: 60). Мы попытаемся выявить этнокультурные особен- 
ности обращений, употребляемых в судебном дискурсе, которые наряду с другими культурно-специфичными особенностями и делают данные варианты отличающимися друг от друга, то есть способствуют формированию и обоснованию их вариативности.

\section{2. Материал и методология исследования}

Материал для исследования был собран из различных источников с применением комплексной методологии сбора данных. Были использованы как первичные источники (словари, газетные статьи, юридические документы), так и вторичные источники - учебники, книги по этикету (Brown \& Rice, Hickey 2008, McPeake 2010 и др.), в том числе и интернет-ресурсы. Данные были проанализированы с опорой на исследования плюрицентричных языков (Clyne 1992, Kloss 1967, Leitner 1992, Muhr \& Marley 2015), контактной вариантологии английского языка (Bolton 2006, 2017; Crystal 2003, Kachru 1986, 1986, 1988, 2008; Low \& Pakir 2017, Proshina 2019, Домашнев 2000, Прошина 2012, 2017 и др.) с применением сравнительного, семантического, прагматического, дискурсивного и культурологического анализа. В центре внимания были как термины, обозначающие судей различного ранга и статуса, так и формы обращений к ним в различных национальных юрисдикциях. Мы ограничились формами обращения, используемыми в устной речи и главным образом в ситуации судебного заседания. Обращения вне суда, а также в письменном дискурсе остались вне нашего внимания. В ходе сопоставительного анализа мы обращали внимание как на сходства, так и различия. Особый акцент был сделан на поиск объяснений выявленных различий, для чего были проанализированы правовые и политические системы стран, говорящих на национальных вариантах английского языка и практикующих Common law (Общее право), которое зародилось в Англии.

В данной статье мы рассматриваем как вокативные (vocative) обращения (1-2), так и аккузативные (accusative) (3-4) (McPeake 2010), которые будем называть прямыми и косвенными соответственно:

(1) Your Honour, there are three affidavits in this case. - Ваша честь, в этом деле имеется три письменных показания под присягой.

(2) My Lord, the third defendant has taken no part in these proceedings. Ваша светлость, третий обвиняемый не принимал участия в судебном процессе.

(3) Does Your Honour have a copy of the defendant's antecedents? - Имеет ли Ваша честь экземпляр прошлой версии обвиняемого?

(4) Does Your Lordship have the claimant's affidavit sworn on the 13th March 2010 ? - Имеется ли у Вашей светлости письменное показание, данное под присягой 13 марта 2010 года?

Также в данном исследовании мы различаем формы обращения (5) и термины референции лица (6) (Dickey 1997), которые могут как совпадать, так и не совпадать: 
(5) Your Honour, there are two witnesses to give testimony. - Ваша честь, два свидетеля готовы дать показания.

(6) Tell Her Honour what you saw when you entered the room. - Расскажите ее чести, что Вы увидели, когда вошли в комнату.

\section{3. Результаты анализа}

Несмотря на то что Соединенное Королевство состоит из четырех частей, его юридическая система представлена тремя различными юрисдикциями: (1) Англия и Уэльс, (2) Шотландия, (3) Северная Ирландия. Хотя все они основаны на общем праве (Common law), в каждой из них есть собственная иерархия судов, свои юридические правила и юридические должности. Этим фактом и обусловлена структура нашего исследования. При этом юридическая система Шотландии является наиболее независимой от центральных властей, что находит отражение и в языке, в том числе и в формах обращения.

\section{1. Обращение к судье в Великобритании}

\subsection{1. Англия и Уэльс}

Юрисдикция Англии и Уэльса характеризуется сложной системой судов, которые различаются по территориальному признаку, типу и тяжести дел. Это может быть Верховный суд, Высокий суд, Апелляционный суд, суды специальной юрисдикции, суды графств, уголовные суды (или суд Короны), магистратские суды и др. Титул судьи зависит от уровня суда, в котором заседает судья, и его позиции. Поскольку формы обращения демонстрируют строгое соотношение с уровнем суда и должностью судьи, то их список весьма представителен (см. Таблицу 1).

Обращения представлены главным образом тремя основными формами: My Lord/My Lady, которые используются в адрес судей вышестоящих судов - Верховного суда, Апелляционного суда и Высокого суда, Your Honour - к судьям округа или графства и Sir/Madam - к судьям местных судов, судов специальной юрисдикции и судьям судов по делам несовершеннолетних. При обращении к коллегии непрофессиональных судей (A bench of lay magistrates) используется собирательное обращение Your worships / your colleagues. При индивидуальном обращении к непрофессиональным судьям обращение Sir/Madam.

В Таблице 1 приведены наиболее распространенные типы судов, расположенные от вышестоящих судов к судам более низкого уровня, должности судей и формы обращения к ним. Данная таблица заимствована нами из (McPeake 2010) и несколько адаптирована с учетом задач исследования. 
Типы судов, должности, формы обращения ${ }^{4}$

\begin{tabular}{|c|c|c|}
\hline ТИП СУДА & должНОСТь & ФОРМА ОБРАЩЕНИЯ \\
\hline $\begin{array}{l}\text { Верховный суд } \\
\text { (Supreme Court) }\end{array}$ & $\begin{array}{l}\text { Судья Верховного суда } \\
\text { (Supreme Court Justice) }\end{array}$ & My Lord/My Lady \\
\hline $\begin{array}{l}\text { Апелляционный суд } \\
\text { (Court of Appeal) }\end{array}$ & Lord Justice & My Lord/My Lady \\
\hline \multirow[t]{4}{*}{ Высокий Суд (High Court) } & Судья (Judge) & My Lord/My Lady \\
\hline & $\begin{array}{l}\text { Любой судья округа в качестве } \\
\text { Судьи Высокого суда }\end{array}$ & My Lord/My Lady \\
\hline & Местный судья (District Judge) & Sir/Madam \\
\hline & Судья-архивариус (Master) & Master \\
\hline \multirow{4}{*}{$\begin{array}{l}\text { Суд Короны (Уголовный } \\
\text { суд) (Crown Court) }\end{array}$} & Судья Высокого суда (High Court Judge) & My Lord/My Lady \\
\hline & Судья округа & Your Honour \\
\hline & $\begin{array}{l}\text { Рекордер или любое лицо } \\
\text { - заместитель судьи округа }\end{array}$ & Your Honour \\
\hline & Рекордер Манчестера/Ливерпуля & My Lord/My Lady \\
\hline $\begin{array}{l}\text { Центральный уголовный } \\
\text { суд (Old Bailey) }\end{array}$ & Любое лицо в роли судьи & My Lord/My Lady \\
\hline \multirow{3}{*}{$\begin{array}{l}\text { Суд графства } \\
\text { (County Court) }\end{array}$} & Судья округа (Circuit Judge) & Your Honour \\
\hline & $\begin{array}{l}\text { Рекордер или любое лицо - замести- } \\
\text { тель судьи округа }\end{array}$ & Your Honour \\
\hline & Местный судья (District Judge) & Sir/Madam \\
\hline \multirow{2}{*}{$\begin{array}{l}\text { Суд специальной юрис- } \\
\text { дикции (Tribunal) }\end{array}$} & Председатель & Sir/Madam \\
\hline & Члены суда & Your colleagues \\
\hline \multirow{3}{*}{$\begin{array}{l}\text { Суд по делам несовер- } \\
\text { шеннолетних } \\
\text { и магистратский суд } \\
\text { (Youth Court and } \\
\text { Magistrates' Court) }\end{array}$} & $\begin{array}{l}\text { Судья местного суда } \\
\text { (District Judge) }\end{array}$ & Sir/Madam \\
\hline & $\begin{array}{l}\text { Председатель коллегии } \\
\text { непрофессиональных мировых } \\
\text { судей } \\
\text { (Chairman of Lay Bench) }\end{array}$ & Sir/Madam \\
\hline & Члены коллегии & $\begin{array}{l}\text { Your colleagues/ } \\
\text { Your worships }\end{array}$ \\
\hline
\end{tabular}

Однако собранные нами из других источников данные свидетельствуют о том, что реальная картина еще более сложная. На основе обобщения полученных в ходе исследования данных был составлен следующий перечень форм обращений к судье в британском английском (BrE), где, помимо названных выше My Lord/My Lady, Your Honour, Sir/Madam, встречаем Judge, Mr Justice, Mrs/Ms Justice, Lord Justice /Lady Justice, Lord Chief Justice, President, Chancellor и др. При этом мы не утверждаем, что составленный нами список обращений является исчерпывающим.

\footnotetext{
${ }^{4}$ Таблица заимствована из (McPeake 2010) и адаптирована с учетом задач исследования.
} 
Формы обращения к судьям в BrE и их должности

\begin{tabular}{|l|l|}
\hline ФОРМА ОБРАЩЕНИЯ & ДОЛЖНОСТЬ \\
\hline Lord Chancellor & Lord Chancellor (Лорд-канцлер, аналог министра юстиции) \\
\hline Lord Chief Justice & Lord Chief Justice (Председатель Верховного суда) \\
\hline Master of the Rolls & Master of the Rolls (Председатель Апелляционного суда) \\
\hline President & $\begin{array}{l}\text { President of the Queen's Bench Division (Председатель одного из } \\
\text { подразделений Высокого суда) }\end{array}$ \\
\hline Chancellor & Chancellor of the High Court (Председатель Высокого суда) \\
\hline Lord Justice / Lady Justice & Lord Justice of the Court of Арреal (Судья Апелляционного суда) \\
\hline $\begin{array}{l}\text { My Lord / My Lady } \\
\text { Mr Justice/ Mrs/Ms Justice }\end{array}$ & Judge of the High Court (Судья высокого суда) \\
\hline My Lord / My Lady & Honorary recorder (Почетный рекордер) \\
\hline Judge & А circuit or district јudge (Судья округа или района) \\
\hline Your Honour & А circuit judge /recorder (Судья округа / рекордер) \\
\hline Sir / Madam & $\begin{array}{l}\text { District judge (Местный судья) или tribunal јиdge (судья специали- } \\
\text { зированного суда) }\end{array}$ \\
\hline
\end{tabular}

Как видим, формы обращения варьируют в зависимости от типа суда и позиции судьи, например, к судье Высокого суда принято обращение My Lord/My Lady, в то время как к судье графства - Your Honour. Однако возможны и более сложные случаи, когда, например, судья Высокого суда слушает дело, относящееся к суду графства. В этом случае к нему необходимо обращаться My Lord/My Lady. Если судья суда графства заседает в качестве судьи в Высоком суде, к нему следует обращаться по правилам Высокого суда и тоже использовать обращение My Lord/My Lady (McPeake 2010).

В отношении употребления форм обращений на основе анализа собранного материла были выявлены некоторые интересные особенности.

К судье обращаются, как правило, в косвенной форме (7-8), местоименное обращение уоu не допустимо 5 :

(7) As your Honour said... - Как сказала Ваша честь.... (нельзя сказать As You said ... - Как Вы сказали...)

(8) Your Lordship may be minded to... - Позвольте привлечь внимание Вашей светлости к ...

Хотя прямая форма обращения также возможна (9-10), по нашим наблюдениям, она употребляется в основном к судьям судов низшей инстанции или невысокой должности:

(9) Sir/Madam, the defendant is content for their matter to be dealt with today. - Сэр/мадам, ответчик доволен тем, что их дело рассматривается сегодня.

(10) If you look at the document marked "A", Master, you will see that... Если Вы посмотрите на документ, помеченный буквой «А», судья (магистратский судья), то вы увидите, что ...

\footnotetext{
${ }^{5}$ Примеры (7 - 13) заимствованы из (McPeak 2010)
} 
При обращении к судьям высшей инстанции прямое обращение часто комбинируется с косвенным. При этом My Lord заменяется на Your Lordship, a My Lady - на Your Ladyship:

(11) My Lady, if I may deal with the points which Your Ladyship has raised... - Ваша светлость (бук.: Моя Леди), если я могу затронуть вопросы, поднятые Вашей светлостью ...

(12) I am happy to tell Your Lordship that the parties have reached terms in this matter. - Я рад сообщить Вашей светлости, что стороны достигли соглашения по этому вопросу.

При обращении к судье в третьем лице, т.е. в референтной функции, употребляются His Lordship/Her Ladyship и His Honour/Her Honour'. Местоимения третьего лица недопустимы:

(13) Describe the layout of the room to His Lordship. - Опишите Его светлости расположение комнаты.

Судьи, в свою очередь, не употребляют личного местоимения первого лица и называют себя The Court (суд): The Court finds ... (Суд считает...), The Court orders ... (Суд постановляет...).

\subsection{2. Шотландия}

Судебная система Шотландии, по сравнению с системой Англии и Уэльса, намного проще, она насчитывает всего 6 должностных уровней. Высшие судебные должности - Lord President of the Court of Session (Лорд-председатель Сессионного суда), возглавляющий гражданские суды, и Lord Justice General (Председатель Высокого суда юстиции), возглавляющий уголовные суды, с 1836 г. совмещаются. Всем судьям, за исключением мирового судьи, после назначения на должность присваивается титул (см. Таблицу 3 ).

Таблица 3

Судебные должности, титулы и формы обращения в суде в шотландском английском (ScE)

\begin{tabular}{|l|l|l|}
\hline \multicolumn{1}{|c|}{ ДОЛЖНОСТь } & \multicolumn{1}{|c|}{ ТИТУЛ } & ФОМА ОБРАЩЕНИЯ В СУДЕ \\
\hline $\begin{array}{l}\text { Lord President of the Court of Session } \\
\text { (Лорд-председатель Сессионного суда) }\end{array}$ & Lord President & Мy Lord \\
\hline $\begin{array}{l}\text { Lord Justice General of Scotland (Лорд- } \\
\text { генеральный судья) }\end{array}$ & Lord Justice General & My Lord \\
\hline Lord Justice Clerk (Лорд-клерк юстиции) & Lord Justice General & My Lady / My Lord \\
\hline $\begin{array}{l}\text { Senator of the College of Justice } \\
\text { (Сенатор Коллегии правосудия) }\end{array}$ & $\begin{array}{l}\text { Lord/Lady + surname } \\
\text { or territorial name }\end{array}$ & My Lord / My Lady \\
\hline Sheriff Principal & $\begin{array}{l}\text { Sheriff Principal } \\
\text { +surname }\end{array}$ & My Lord / My Lady \\
\hline Sheriff & Sheriff +surname & My Lord / My Lady \\
\hline Justice of the Реасе (Мировой судья) & ----- & Your Honour \\
\hline
\end{tabular}


Что касается форм обращения, используемых в суде, то, как показывает наш материал, их набор весьма ограничен: к мировому судье используется обращение Your Honour (Ваша честь), ко всем остальным, вне зависимости от судебного ранга, - My Lord / My Lady. Данный факт, на наш взгляд, свидетельствует о значительной дистанцированности судебной системы Шотландии от системы Англии и Уэльса и ее большей демократичности.

\section{2. Республика Ирландия}

Тенденция к упрощению форм обращений в суде еще более отчетливо проявляется в ирландском английском (IrE), где наблюдается их периодическое реформирование.

В 2006 году Комитет по правилам Высших судов (Superior Courts Rules Committee) принял решение отказаться от британских практик обращения к судье My Lord и Your Lordship и ввел некоторые ирландские термины ${ }^{6}$.

По его решению в качестве обращений к председателям судов высшего уровня - Верховного суда (the Supreme Court) и Высокого суда (the High Court) - рекомендованы соответствующие титулы на ирландском или английском языках: The Honourable Mr/Mrs/Ms/Miss Justice + фамилия (An Breitheamh Onórach Uasal + фамилия). В суде к ним обращаются либо по титулу, либо по формуле обращения Judge (судья) или A Bhreithimh (Ir.), которая также используется и в адрес других членов судов высшего уровня. Обращение Your Lordships, употреблявшееся к двум и более судьям, было заменено ирландским обращением An Chúirt и соответствующим английским The court (суд).

К судьям окружного и местного судов, к которым ранее использовалось обращение Justice, стало также применяться обращение Judge. Заметим, что до 2006 года к судьям округа использовалось обращение My Lord или A thiarna (Ir.), а к судьям местных судов до 1991 года обращались Your Worship или d'Onóra (Ir.). Интересно отметить, что в третьем лице в качестве референтной формы к ним также используется Judge. Однако по отношению к судьям Верховного суда и Высокого суда, называемым в третьем лице как в суде, так и вне суда, сохранились официальные формулы The Honourable Mr/Miss/Mrs/Ms Justice + фамилия. Согласно имеющимся источникам употребление обращения Justice без формулы почтения и фамилии в данной ситуации считается некорректным ${ }^{7}$.

Таким образом, налицо вытеснение традиционных английских форм обращения и их замена более демократичными формами, как английскими, так и ирландским (см. Таблицу 4), что, по мнению граждан Ирландии, делает их

${ }^{6}$ Amendment to: Order 119. S.I. No. 196 of 2006: Rules of the Superior Courts (Mode of Address of Judges) $2006 \mathrm{http} / / / w w w . c o u r t s . i e /$ rules.nsf/8652fb610b0b37a980256db700399507/ 6c4049b0653cad3380256d2b0046b3e6?OpenDocument.

${ }^{7}$ Coulter. Carol. Manner of addressing judges in court to change. The Irish Times (Mon, Apr 10, 2006). 
систему обращений более аутентичной, отличающейся от английской, а также сокращает дистанцию между ними и судьями, что делает их более равными․․

Таблича 4

Название суда, титулы и формы обращения к судьям в ирландском английском (IrE)

\begin{tabular}{|l|l|l|l|}
\hline ТИП СУДА & $\begin{array}{l}\text { ОФИЦИАЛЬНОЕ ИМЕ- } \\
\text { НОВАНИЕ в 3-ем лице }\end{array}$ & \multicolumn{2}{|l|}{ ФОРМА ОБРАЩЕНИЯ } \\
\cline { 3 - 4 } & & Устаревшая & Современная \\
\hline $\begin{array}{l}\text { Высшие суды } \\
\text { (Supreme Court, } \\
\text { High Court, Court } \\
\text { of Appeal) }\end{array}$ & $\begin{array}{l}\text { The Honourable Mr/ } \\
\text { Mrs/Ms/Miss Justice + } \\
\text { фамилия }\end{array}$ & $\begin{array}{l}\text { My Lord } \\
\text { Your Lordship } \\
\text { Our Lordships }\end{array}$ & $\begin{array}{l}\text { The Honourable Mr/ } \\
\text { Mrs/Ms/Miss Justice + } \\
\text { фaмилия / Judge } \\
\text { The court / An Chúirt } \\
\text { (Ir.) }\end{array}$ \\
\hline $\begin{array}{l}\text { Cуд округа } \\
\text { (Circuit court) }\end{array}$ & $\begin{array}{l}\text { His/Her Honour Judge + } \\
\text { Surname }\end{array}$ & Lord (A thiarna) & Judge / A Bhreithimh) \\
\hline $\begin{array}{l}\text { Mecтный cуд } \\
\text { (District Court) }\end{array}$ & Judge + фомамилия & Your Worship(d'Onóra). & Judge / A Bhreithimh) \\
\hline
\end{tabular}

\section{3. Канада}

Формы обращения к судье в канадском английском (CanE) сочетают как традиционные формы, так и современные, при этом наблюдается их варьирование по территориальному принципу.

В Канаде тенденция к упрощению обращений нашла поддержку Верховного Суда, который в 2009 году выпустил специальные рекомендации по обращениям в суде ${ }^{9}$. Согласно этим и последующим рекомендациям предлагается воздерживаться от использования в адрес судей традиционных английских обращений My Lord / My Lady, Your Lordship / Your Ladyship и заменять их обращениями Justice или Mr Justice / Madam Justice + фамилия ${ }^{10}$. В итоге суды высшего и федерального уровней перешли на обращение к судьям Mister/Madam (Chief) Justice + фамилия.

Однако этим рекомендациям не всегда следуют в высших судах провинций и территорий, где формы обращений варьируются в зависимости от административного деления. В некоторых провинциях судьи вышестоящих судов предпочитают обращения Mister Justice / Madam Justice, однако в других сохраняются традиционные обращения My Lord / My Lady. Так, например, провинция Британская Колумбия не приняла рекомендаций

8 The Circuit Brief http://thecircuitbrief.blogspot.com/2011/02/addressing-judge-incourt.html

${ }^{9}$ Notice to the parties and the profession addressing judicial officers in court, September 3 , 2009. http://www.fct-cf.gc.ca/fct-cf/pdf/Notice $\% 20-\% 20$ Form $\% 20$ of $\% 20$ Address $\% 20$ ENG $\% 20$ sept-3-2009.pdf

10 Supreme Court of Canada: https:10. How does one address a judge? // www.scc-csc.ca/contact/faq/qa-qr-eng.aspx

Styles of address: The official website of the Government of Canada https://www.canada.ca/en/canadian-heritage/services/protocol-guidelines-special-event/styles-address.html 
Верховного суда и в ней по-прежнему к судьям Верховного и Апелляционного судов используются обращения My Lord / My Lady и Your Lordship / Your Ladyship, а к судьям провинциальных уровней - Your Honour и Your Worship. Эти правила подтверждаются и инструкцией 2019 года ${ }^{11}$.

К судьям нижестоящих судов традиционное обращение Your Honour, как правило, сохраняется, однако также используется и обращение Judge + фaмuлия. Исключение составляет провинция Онтарио, где к судьям всех уровней используется обращение Mister Justice / Madam Justice. Традиционная практика обращения к мировым судьям Your Worship постепенно вытесняется обращением Your Honour ${ }^{12}$. К судьям, именуемым master, обращаются Mr. Master или просто Sir. В Британской Колумбии к ним обращаются Your Honour (Ваша Честь).

\section{4. Австралия}

B австралийском английском (AusE) система обращений к судьям также довольно простая. Она регулируется Федеральным законом о суде ${ }^{13}$. При этом, как показывают специальные инструкции по поведению в суде ${ }^{14}$, существует множество нюансов, свидетельствующих о достаточно высоком уровне формальности в судебном дискурсе. В судах высшего федерального уровня, а также в судах штатов к судьям используется обращение Your Honour (14). В случае, если заседание суда ведет главный судья (Chief Justice), к нему используется форма обращения Chief Justice (15).

(14) Is that a convenient time, your Honour? - Это удобное время, Ваша честь?

(15) Yes, Chief Justice. - Да, главный судья.

Согласно этикету обращение к судье делается исключительно в косвенной форме (16-18):

(16) Your Honour ordered that... - Ваша честь постановила, что... 15

(17) As your Honour said a moment ago ... - Как Ваша честь сказала минуту назад...

(18) Might I invite your Honour to turn to document 45 of the bundle of documents and then to page 20 of that document? - Могу я пригласить

${ }^{11}$ Forms of address in Court and in the Courthouse (Last revised August 08, 2019) https://www.courthouselibrary.ca/how-we-can-help/our-legal-knowledge-base/forms-address

${ }^{12}$ Notice to the parties and the profession addressing judicial officers in court, September 3 ,

2009 http://www.fct-cf.gc.ca/fct-cf/pdf/Notice\%20-\%20Form\%20of\%20Address $\% 20$ ENG $\% 20$ sept-3-2009.pdf

${ }_{13}$ The Federal Court of Australia Act 1976 s6(6) http://classic.austlii.edu.au/au/legis/cth/ consol_act/fcoaa1976249/s6.html

${ }^{14}$ Court Etiquette: 50 tips on how to behave in and for the courtroom http://www.hearsay.org.au/index.php?option

${ }^{15}$ Примеры (16-20) заимствованы из Court Etiquette: 50 tips on how to behave in and for the courtroom http://www.hearsay.org.au/index.php?option 
Вашу честь обратиться к документу 45 из пакета документов, а затем к странице 20 этого документа?

Местоименные обращения в форме второго лица (19), как и императивные формы (20), не допускаются:

(19) As you said a moment ago ... - Как Вы сказали минуту назад...

(20) Now just look at document page 20 in document 45 . -

А теперь посмотрите на страницу 20 документа 45.

В качестве референтной формы к судьям употребляются Chief Justice, Justice, Judge. При представлении высокопоставленного судьи за пределами суда следует представить его как Justice (судья), а далее в разговоре называть его Judge (судья) ${ }^{16}$.

Ярким примером, свидетельствующим о довольно высокой степени формальности австралийского судебного дискурса, является приветственная фраза, адресованная судьям. Прямое обращение Good morning Your Honour (Доброе утро, Ваша честь), считается фамильярным и его рекомендуется избегать.

Адвокату предписывается обращаться к суду следующим образом:

(21) May it please the court, my name is [surname] initials [say your initials], solicitor of [practice name] and I appear for the [party] ${ }^{17}$. (Букв.:

Пусть это доставит удовольствие суду, меня зовут [фамилия], инициалы [ваши инициалы], адвокат [специализация], и я выступаю от имени стороны [назовите сторону]

К магистратским судьям Федерального суда следует обращаться Your Honour или Federal Magistrate. В отличие от Англии к ним нельзя обращаться Your Worship. Вне суда в их адрес допустимы обращения Mr /Ms, Sir / Madam. Согласно нашим данным обращение Your Honour применимо к судьям всех местных судов, где к некоторым судьям возможны и другие формы обращения, как например, Sir/Madam в административном суде штата Виктория.

\section{5. Новая Зеландия}

В Новой Зеландии система форм обращения к судьям довольно проста. Они изложены в специальной инструкции, регулирующей поведение в суде и содержащей нормы судебного этикета ${ }^{18}$, которые предписывают обращаться к судье Your Honour или Sir / Madam. Обращение Your Honour часто

${ }^{16}$ The dummies' guide to addressing judicial officers https://www.uts.edu.au/about/facultylaw/news/dummies-guide-addressing-judicial-officers

${ }^{17}$ The dummies' guide to addressing judicial officers https://www.uts.edu.au/about/facultylaw/news/dummies-guide-addressing-judicial-officers briefings

${ }^{18}$ Practice briefing: Addressing members of the Judiciary www.lawsociety.org.nz > practice- 
употребляется не прямо, а косвенно, как, например, во фразе привлечения внимания (22-23) или при принятии к сведению решения суда.

(22) If your Honour pleases... (Букв.: Если Ваша честь пожелает...)

(23) As the Court / your Honour pleases... (Букв.: Как угодно Суду / Как пожелает Ваша честь) ${ }^{19}$

В качестве референтных форм в отношении судей используются justice + фамилия и judge + фамилия (добавление имени допустимо только в случаях совпадения фамилий). При этом, как и в австралийском английском, они демонстрируют четкое разграничение по статусу: Justice + фамилия употребляется к судьям более высокого уровня, а именно - к судьям Верховного суда, Апелляционного суда и Высокого суда, в то время как judge + фамилия - к судьям местных судов. В последнем случае возможно и обращение без фамилии - Judge, которое также употребляется в неформальной обстановке и вне суда:

(24) Pleased to meet you Judge (Рад с Вами познакомиться, судья).

\section{6. США}

При достаточно простой системе форм обращения в американском английском (AmE) официальные правила судебного этикета США предписывают соблюдение строгих формальностей в зале суда. Игнорирование этих правил адвокатами может привести к санкциям, начиная от строгого предупреждения до отмены слушания и отстранения от работы из-за неуважения к суду ${ }^{20}$.

В качестве форм обращения к судьям в американском английском рекомендуются Your Honor, Judge, Judge + фамилия. Во многих штатах к судье обращаются Your Honor (Ваша честь) или Judge (Судья). Как показывают проанализированные источники, обращение Judge более широко используется адвокатами и сотрудниками, в то время как истец или ответчик могут использовать любое из них.

Некоторые суды более формальны, чем другие, и могут иметь свои собственные правила. Например, Верховный Суд округа Лос Анжелес ввел правило, согласно которому к судье следует обращаться в зале суда только как Your Honor. Такие обращения, как Judge (судья), Judge + фамилия, ma'am /sir, считаются неуважительными ${ }^{21}$, хотя во многих других штатах они являются приемлемыми и вполне уважительными.

19 Данная фраза произносится при вставании и даже в тех случаях, когда участники процесса с решением суда не согласны.

${ }^{20}$ How to Address a Female Attorney: 7 Steps (with Pictures) www.wikihow.com > ... > Civil Litigation

${ }^{21} \mathrm{http}: / /$ www.courts.ca.gov/documents/ca_code_judicial_ethics.pdf 
Согласно некоторым источникам ${ }^{22}$, использование терминов, указывающих на гендерные различия (Mr., Ms., Madam), считается в настоящее время в американском судебном дискурсе проявлением сексизма.

К судьям Верховного Суда США и некоторых штатов используется обращение Justice+ фамилия (так же как в Австралии и Новой Зеландии). Формальное обращение к Верховному Судье Соединенных Штатов - Mr. Chief Justice или Chief Justice + фамилия.

К федеральным магистратам (независимым судьям, которых в США 572), следует обращаться Your Honor или Judge, а при ссылке на них в третьем лице использовать обращение The Honorable (Hickey 2008).

\section{4. Заключение}

В данном исследовании были проанализированы именования судей и формы обращения к судье в национальных вариантах английского языка британском, ирландском, канадском, австралийском, новозеландском и американском. Мы ограничились формами обращений, используемыми в устной речи и главным образом в ситуации судебного заседания. Предварительные результаты исследования выявили как сходства, так и различия, которые наблюдаются в наименованиях судей различного ранга и в формах обращения к ним.

Наиболее сложная система обращений с соблюдением строгой иерархии до сих пор традиционно сохраняется в британском английском, при этом уже в шотландском наблюдается ее значительное упрощение. В ирландском английском, который также идет по пути упрощения форм обращений к судьям, наряду с английскими активно практикуются ирландские (гэльские) термины, использование которых закреплено официальными документами. Тенденция к демократизации системы обращений в суде наблюдается и в других вариантах английского языка, в том числе и под влиянием государственной политики. Так, в Канаде и Австралии на законодательном уровне были приняты документы, упрощающие формы обращения в суде. Для американского судебного дискурса также характерна демократичность, которая проявляется в минимизации форм обращения к судьям, однако при этом в связи с федерализацией государства единые правила обращения отсутствуют и варьируют в зависимости от штата.

Выявленные различия обусловлены комплексом исторических, политических и социальных причин, которые требуют специального дальнейшего изучения. Среди них можно отметить, в частности, различную степень открытости общества к демократизации его правовой системы, стремление страны либо следовать традициям, установленным в британском судебном дискурсе, либо демонстрировать свою уникальность и независимость от бывшей метрополии.

\footnotetext{
${ }^{22} \mathrm{https}$ //www.daytranslations.com/blog/2015/05/the-use-of-honorifics-in-the-legal-profession-6273/
} 
Мы не претендуем на полноту исследования. Вопросы функционирования обращений как в вокативной, так и референтной фунциях, требуют дальнейшего и более глубокого изучения. За рамками остались и вопросы использования обращений вне судебного заседания, а также в письменной речи. Тем не менее, несмотря на ограниченный характер, исследование дает новые данные, иллюстрирующие, что лексическая и дискурсивная вариативность, наблюдаемая в юридической сфере, способствует формированию вариантов плюрицентричных языков и может рассматриваться как их конституирующий элемент.

Проведенное исследование показало, что при анализе юридического английского и выявлении его особенностей в различных вариантах английского языка следует учитывать и особенности юридических систем, которые, несмотря на принадлежность к общему праву (Common Law), в значительной степени являются независимыми.

Результаты могут способствовать изучению плюрицентричных языков, найти применение в лексикографической практике, а также в преподавании юридического английского для студентов-юристов.

(C) В.И. Озюменко, 2020 (c)creative

This work is licensed under a Creative Commons Attribution 4.0 International License https://creativecommons.org/licenses/by/4.0/

\section{Благодарности и финансирование:}

Публикация подготовлена при поддержке Программы РУДН «5-100».

\section{СПИСОК ЛИТЕРАТУРЫ / REFERENCES}

Домашнев А.И. Вопросы исследования плюрицентрического развития современного английского языка // Res Linguistica: К 60-летию доктора филол. наук, проф. В.П. Нерознака. М.: Академия. 2000. C. 90-97. [Domashnev A.I. 2000. Voprosy issledovaniya plyuritsentricheskogo razvitiya sovremennogo angliiskogo yazyka. In Res Linguistica, 90-97. Moscow.: Akademiya]

Которова Е. Г. Анализ терминов родства с помощью Естественного Семантического Метаязыка: подход Анны Вежбицкой // Russian Journal of Linguistics (Вестник Российского университета дружбы народов. Серия: Лингвистика). 2018. Т. 22, № 3. C. 701-710. DOI: 10.22363/2312-9182-2018-22-3-701-710 [Kotorova, Elizaveta. 2018. Analysis of Kinship Terms using Natural Semantic Metalanguage: Anna Wierzbicka's approach. Russian Journal of Linguistics 22 (4). 701-710] DOI: 10.22363/2312-9182-201822-3-701-710.

Ларина Т. В., Сурьянараян Н., Юрьева Ю. Б. Социокультурный контекст, формы обращения и стили коммуникации (на примере британского и индийского вариантов английского языка) // Вестник Волгоградского государственного университета. Серия 2. Языкознание. 2019. T. 18, № 3. С. 39-51. [Larina, Tatiana, Neelakshi Suryanarayan \& Julia Yuryeva. 2019. Socio-cultural context, address forms and communicative styles: 
A case study of British and Indian Englishes. Vestnik Volgogradskogo gosudarstvennogo universiteta. Seriya 2. Yazykoznanie 18 (3). 39-51] DOI: https://doi.org/10.15688/jvolsu2.2019.3.3

Озюменко В.И., Чилингарян. К.П. Полисемантичность английской юридической лексики как проблема перевода // Russian Journal of Linguistics (Вестник РУДН. Серия Лингвистика. 2015. №2. С. 180-193. [Ozyumenko, Vladimir \& Kamo Chilingaryan K (2015) Polysemy of English legal lexis and the problems of translation. Russian Journal of Linguistics 2. 180-193]

Озюменко В.И. Лексико-семантические поля judge и судья в английском и русском языках // Russian Journal of Linguistics (Вестник Российского университета дружбы народов. Серия: Лингвистика). 2016. Т. 20. № 3. С. 195-213 [Ozyumenko, Vladimir. 2016. Lexical and Semantic Fields Judge and Sudya in the English and Russian Languages. Russian Journal of Linguistics 20 (3). 195-213]

Прошина 3.Г. Динамика развития английского языка в его региональных вариантах. Вестник ИГЛУ. Серия «Филология». 2012. Т. 2. 18. No C. 200-206 [Proshina Z.G. 2012. Dinamika razvitiya angliiskogo yazyka v ego regional'nykh variantakh. Vestnik IGLU. Seriya «Filologiya». 2 (18). 200-2006]

Прошина 3.Г. Контактная вариантология английского языка: Проблемы теории. М.: Флинта, Наука 2017 [Proshina, Zoya. 2017. World Englishes Paradigm. Moscow: Flinta, Nauka]

Afful, Joseph.2006. Address Terms among University Students in Ghana: A Case Study. Language and Intercultural Communication 6 (1). 76-91 DOI: 10.1080/14708470608668909

Aliakbari, Mohammad \& Toni Arman. 2008. The Realization of Address Terms in Modern Persian in Iran: A Sociolinguistic Study. Linguistik Online 35(3). 3-12.

Bolton, Kingsley. 2006. Where WE stands: Debate in world Englishes. World Englishes 24 (1). $69-83$.

Bolton, Kingsley. 2017. World Englishes: Current trends and future directions. In Low, Ee Ling \& Anne Pakir (eds.). World Englishes: Rethinking Paradigms. Routledge.

Chesnokova, Olga. 1996. Dialogic Motivation of Spanish Forms of Address In Dialoganalyse VI. Referate der 6. Arbeitstangung. Prag, Teil 1, Max Niemeyer Verlag Tübingen. 487491.

Chilingaryan, Kamo, Tatiana Larina \& Vladimir Ozyumenko. 2016a. "Judge" and "sudya" in the English and Russian languages: In search for terminological adequacy. In Proceedings of INTCESS 2017 4th International Conference on Education and Social Sciences, 6-8 February 2017 — Istanbul, Turkey. ISBN: 978-605-64453-9-2. 369-376. http://www.ocerint.org/intcess17_epublication/abstracts/a19.html

Chilingaryan, Kamo, Tatiana Larina \& Vladimir Ozyumenko. 2016b. Ambiguity of culturebound terms in legal English and Russian. In SGEM 2016 Conference Proceedings, ISBN 978-619-7105-70-4 / ISSN 2367-5659, 24-31 August, 2016, Book 1 Vol. 1. 529-540. DOI: 10.5593/SGEMSOCIAL2016/B11/S03.068 http://sgemsocial.org/ssgemlib/ spip.php?article2271

Clyne, Michael. 1992. Introduction. In Michael Clyne (ed.), Pluricentric Languages: Differing Norms in Different Nations. Mouton de Gruyter: Berlin / New York.

Clyne, Michael. 2009. Address in intercultural communication across languages. Intercultural Pragmatics 6(3). 395-409.

Clyne, Michael, Catrin Norrby \& JaneWarren. 2009. Language and Human Relations: Style of Address in Contemporary Language. Cambridge: Cambridge University Press.

Crystal, David. 2003. English as a global language. 2 ed-n. Cambridge: Cambridge University Press. New York: Mouton de Gruyter. 
Dickey, Eleanor.1997. Forms of address and terms of reference. Journal of Linguistics 33 (2). 255-274.

Hickey, Robert. 2008. Honor \& Respect: The Official Guide to Names, Titles, and Forms of Address. Protocol School of Washington.

Hughson, Jo-anne. 2009. Diversity and Changing Values in Address: Spanish Address Pronoun Usage in an Intercultural Immigrant Context. Peter Lang: Frankfurt am Mein.

Kachru, Braj B.1985. Standards, codification and sociolinguistic realism. The English language in the outer circle. In Randolph Quirk and H.G. Widdowson (eds.) English in the World: Teaching and Learning the Language and Literatures, 11-0. Cambridge: Cambridge University Press.

Kachru, Braj. 1986. The alchemy of English. Oxford: Pergamon.

Kachru, Braj B. 1988. The sacred cows of English. English Today 16 (4). 3-8.

Kachru, Braj B. 2008. World Englishes in world contexts. In H. Momma \& M. Matto (eds.), A companion to the history of the English Language, 567-580. Oxford: Wiley-Blackwell.

Khalil, Amr, Tatiana Larina \& Neelakshi Suryanarayan. 2018. Sociocultural competence in understanding forms of address: case study of kinship terms in different cultural contexts. EDULEARN18 Proceedings. 10th International Conference on Education and New Learning Technologies. Palma de Mallorka, Spain. 2-4 July, 2018. Pages: 3038-3045, doi: 10.21125/edulearn.2018.0799 ISBN: 978-84-09-02709-5

Kloss, Heinz. 1967. Abstand languages' and 'ausbau languages. Anthropological Linguistics 9 (7). $29-41$.

Larina, Tatiana \& Suryanarayan Neelakshi. 2013. Madam or aunty ji: address forms in British and Indian English as a reflection of culture and cognition / Monika Reif, Justina A. Robinson, Martin Putz (eds.), Variation in Language and Language Use, 190 - 217. Frankfurt am Mein: Peter Lang.

Larina Tatiana \& Amr Khalil. 2018. Arabic Forms of Address: Sociolinguistic Overview. The European Proceedings of Social and Behavioural Sciences EpSBS, Volume XXXIX WUT 2018: Word, Utterance, Text: Cognitive, Pragmatic and Cultural Aspects, 229 309. Future Academy. DOI: http://dx.doi.org/10.15405/epsbs.2018.04.02.44

Leitner, Gerhard.1992. English as a pluricentric language. In Michael Clyne M (ed.), Differing Norms in Different Nations, 179-238. Mouton de Gruyter: Berlin / New York.

Low, Ee-Ling \& Anne Pakir (eds.). 2017. World Englishes: Rethinking Paradigms. Routledge. McPeake, Robert (ed.). 2010. Advocacy.15-th ed-n. Oxford.

Muhr, Rudolf. 2012. Non-dominant Varieties of pluricentric Languages Getting the Picture. In memory of Michael Clyne. Österreichisches Deutsch - Sprache der Gegenwar Publisher: Peter Lang Verlag, Wien, Frankfurt ISBN: 978-3-631-62024-3

Muhr, Rudolf \& Dawn Marley D (eds.) 2015 Pluricentric Languages: New Perspectives in Theory and Description. Series: Österreichisches Deutsch - Sprache der Gegenwart. Frankfurt am Main, Berlin, Bern, Bruxelles, New York, Oxford, Wien.

Proshina, Zoya. 2019.Elaborating on the Expanding Circle. World Englishes. 38 (1-2). Special Issue: Honoring the Life and Work of Braj B. Kachru. 233-244.

Rhee, Seongha. 2019. Politeness pressure on grammar: The case of first and second person pronouns and address terms in Korean. Russian Journal of Linguistics. 23 (4). 950 - 974. doi: 10.22363/2312-9182-2019-23-4-950-974.

Scherrer, Yves, Tanja Samardžić \& Elvira Glaser. 2019. Digitising Swiss German: how to process and study a polycentric spoken language. Language Resources and Evaluation 53 (4). 735-769.

Wierzbicka, Anna. 2013. Kinship and Social Cognition in Australian Languages: Kayardild and Pitjantjatjara. Australian Journal of Linguistics. 33 (3). 302-321. DOI: 10.1080/ 07268602.2013 .846458 
Wong, Jock. 2006. Contextualizing aunty in Singaporean English. World Englishes 25 (3-4). $451-466$.

\section{Словари, учебники и Интернет ресурсы / Dictionaries, textbooks and Internet Resources}

Amendment to: Order 119 S.I. No. 196 of 2006: Rules of the Superior Courts (Mode of Address of Judges) http://www.courts.ie/rules.nsf/8652fb610b0b37a980256db700399507/ 6c4049b0653cad3380256d2b0046b3e6?OpenDocument

Appearing in courts and tribunals https://www.lawsociety.org.nz/practice-resources/new-zealand-law-society-guide-for-new-lawyers/appearing-in-courts-and-tribunals

Black's Law Dictionary — Free Online Legal Dictionary. https://thelawdictionary.org/article/best-way-to-write-a-professional-letter-to-a-judge/

Brown, Gillian D. \& Sally Rice. 2007. Professional English in Use: Law. Cambridge University Press.

California Code of Judicial Ethics http://www.courts.ca.gov/documents/ca_code_judicial_ethics.pdf

Coulter, Carol. 2006. Manner of addressing judges in court to change The Irish Times Mon, Apr 10, 2006.

Court Etiquette: 50 tips on how to behave in and for the courtroom http://www.hearsay.org.au/index.php?option

Courthouse libraries bc https://www.courthouselibrary.ca/how-we-can-help/our-legalknowledge-base/forms-address

Day translatios https:/www.daytranslations.com/blog/2015/05/the-use-of-honorifics-in-thelegal-profession-6273/

How to Address Judges/Justices. https://law.richmond.edu/docs/cdo/how-to-addressjudges.pdf

Legal Beagle https://legalbeagle.com/8087737-address-letter-supreme-court-judge.html

Legal Beagle https://legalbeagle.com/8118126-address-magistrate.html How to Address a Magistrate

Modes_of_Address:_Introduction https://learnmore.lawbore.net/index.php/

Notice to the parties and the profession addressing judicial officers in court, September 3, 2009 http://www.fct-cf.gc.ca/fct-cf/pdf/Notice\%20-\%20Form\%20of\%20Address\%20ENG\% 20sept-3-2009.pdf

On-line guide to forms of address http://www.formsofaddress.info/Judge_US.html

QUORA https://www.quora.com/How-do-lawyers-prosecutor-introduce-themselves-in-thecourt

Styles of address: The official website of the Government of Canada https://www.canada.ca/en/canadian-heritage/services/protocol-guidelines-special-event/ styles-address.html

Supreme Court of Canada: https:10. How does one address a judge?//www.scc-csc.ca/contact/faq/qa-qr-eng.aspx

The Circuit Brief http://thecircuitbrief.blogspot.com/2011/02/addressing-judge-in-court.html

The dummies' guide to addressing judicial officers https://www.uts.edu.au/about/facultylaw/news/dummies-guide-addressing-judicial-officers

The Federal Court of Australia Act 1976 s6(6) http://classic.austlii.edu.au/au/legis/cth/consol_act/fcoaa1976249/s6.html

The New Zealand Law Society: Practice briefing: Addressing members of the Judiciary — NZ Law Society www.lawsociety.org.nz> practice-briefings 
How to Address a Judge of a United States Federal Court http://www.formsofaddress.info/ FOA home.html

\section{Article history:}

Received: 26 May2019

Revised: 18 July 2019

Accepted: 25 September 2019

\section{История статьи:}

Дата поступления в редакцию: 26 мая 2019

Дата принятия к печати: 25 сентября 2019

\section{Bionote:}

VLADIMIR I. OZYUMENKO, PhD, Associate Professor at Law Institute, RUDN University. Research interests: legal English, theory and practice of translation, media discourse, intercultural communication.

\section{Contact information:}

E-mail: ozyumenko-vi@rudn.ru

Address: Moscow 117198, Miklukho-Maklaya, 6.

ORCID https://orcid.org/0000-0001-7587-3007

\section{Сведения об авторе:}

ВЛАДИМИР ИВАНОВИЧ ОЗЮМЕНКО — кандидат филологических наук, доценТ, доцент кафедры иностранных языков Юридического института Российского университета дружбы народов. Сфера научных интересов: юридический английский, теория и практика перевода, медиадискурс, межкультурная коммуникация.

\section{Контактная информация:}

E-mail: ozyumenko-vi@rudn.ru

Адрес: Москва 117198, ул. Миклухо-Маклая, 6.

ORCID https://orcid.org/0000-0001-7587-3007 